\title{
Conditioned reinforcement of lever-pressing in rats by a brief stimulus and schedule of primary reinforcement
}

\author{
DONALD W. ZIMMERMAN, Carleton \\ University, Ottawa 1, Canada
}

A stimulus controlling terminal component responding in a chained schedule was presented briefly after responses in the initial component on a variable-interval schedule, without subsequent primary reinforcement, under conditions in which rate in the initial component was low, and rate increased. The reinforcing capacity of the stimulus was greater with CRF in the terminal component than with FI 2-min and was not affected by substitution of a DRO contingency for $C R F$.

Brief exteroceptive stimuli that are paired regularly with food or water can maintain typical patterns of responding over extended periods of time (Byrd \& Marr, 1969; Kelleher, 1966; Zimmerman, 1969; Zimmerman, Hanford, \& Brown, 1967). In the present experiment, lever pressing by rats was controlled by a stimulus consisting of a light and tone. Responses on Lever 1 produced the stimulus; in its presence, responses on Lever 2 produced primary reinforcement. Later, the stimulus was presented briefly after responses on Lever 1 without subsequent primary reinforcement of responses on Lever 2 . While the exteroceptive stimulus controlled responding in a (heterogeneous) chained schedule, its conditioned reinforcing properties were examined by a procedure resembling the brief stimulus presentations in the above studies. Changes were made in the schedule of reinforcement in the presence of the stimulus on Lever 2 , and effects on its reinforcing capacity when presented after responses on Lever 1 were observed.

\section{METHOD}

The Ss were four Sprague-Dawley male albino rats, about 95 days old at the beginning of the experiment. They were given daily 1 -h sessions under $22-\mathrm{h}$ water deprivation. Food was continuously available in the home cages.

The apparatus, which has been described elsewhere (Zimmerman, 1969a, b, c), was a modified Gerbrands Model C-3 chamber with a liquid feeder and two levers on opposite walls, enclosed in a ventilated ice chest. Stimuli were two $7.5-\mathrm{V}$ pilot limps with white crystals and a 750-1/z tone from an audio generator, Responses were recorded on Gerbrands cumulative recorders.

During a 12-day period, responding on both levers was established. At the end of this period, the schedule was as follows. Each response on Lever 1 produced the stimulus (two lights and a tone). The first response on Lever 2 terminated the stimulus and produced operation of the liquid feeder, with access to $.1 \mathrm{cc}$ of water for $5 \mathrm{sec}$. At this point, the schedule was chain CRF CRF. Responses on Lever 2 in the absence of the stimulus had no scheduled consequences.

Next, the schedule on Lever 1 was changed to FI 2-min-that is, chain FI 2-min CRF was established. Finally, the schedule on Lever 2 was changed to FI 2-min, so that chain FI 2-min FI 2-min was in effect. The first change lasted for 14 sessions and the second for 12 sessions.

Throughout the remainder of the experiment, the stimulus occurred after responses on Lever 1 on a 2-min fixed-interval schedule (FI 2-min), with a differential reinforcement of other behavior (DRO) contingency added. The stimulus was presented regularly at $2-\mathrm{min}$ intervals if a response on Lever 1 had not occurred within the preceding $6 \mathrm{sec}$ at the scheduled time of presentation; otherwise, the stimulus was postponed until $6 \mathrm{sec}$ after the last response. The first response on Lever 2 terminated the stimulus and produced primary reinforcement. This was a (hetergeneous) chained schedule, in which the first component was tandem FI 114-sec DRO 6-sec and the second component CRF. Throughout this paper, the first component is designated FI 114-sec DRO 6-sec. This schedule continued for 16 sessions.
Later, the stimulus was presented concurrently on a 50 -sec variable-interval schedule (VI 50-sec) after responses on Lever 1; on these occasions, the first response on Lever 2 terminated the stimulus but did not produce primary reinforcement. Under this procedure, association of stimulus and primary reinforcement occurred regularly but only on occasions when responses on Lever 1 were not followed immediately by primary reinforcement, while responding on Lever 1 was maintained by the stimulus without primary reinforcement. This schedule continued for 10 sessions.

FI 2-min Schedule on Lever 2

Next, the VI $50-\mathrm{sec}$ schedule of stimulus presentation was omitted, and the original FI 114-sec DRO 6-sec schedule continued for 8 sessions. At the same time, the schedule of primary reinforcement on Lever 2 was changed from CRF to FI 2-min. Finally, the concurrent VI 50-sec schedule of stimulus presentation was added. On the VI 50-sec schedule, the first response on Lever 2 terminated the stimulus as before. On occasions when responses on Lever 2 produced primary reinforcement, the schedule on Lever 2 was FI 2-min. The concurrent schedule lasted 10 sessions.

\section{DRO Schedule on Lever 2}

The same procedures described above were repeated with a DRO contingency on Lever 2 in addition to that on Lever 1. First, the schedule was DRO 6-sec. After presentation of the stimulus, the liquid feeder operated $6 \mathrm{sec}$ later if a response on Lever 2 had not occurred within that period; otherwise, operation was postponed until $6 \mathrm{sec}$ after the last response. Then, as before, the VI 50-sec schedule of stimulus presentations after responses on Lever 1 was added. Next, a FI 114-sec DRO 6-sec schedule was established on Lever 2, and the VI 50-sec schedule was added 1ater. Procedures are summarized in Table 1.

RESULTS AND DISCUSSION

The chain FI 2-min CRF schedule

\begin{tabular}{llr} 
& Table 1 & Sessions \\
\hline Schedule on Lever 1 & Schedule on Lever 2 & $1-16$ \\
FI 2-min & CRF & $17-26$ \\
FI 2-min & FI 2-min & $27-42$ \\
FI 114-sec DRO 6-sec & CRF & $53-60$ \\
& FI 2-min & $71-78$ \\
& DRO 6-sec & $89-96$ \\
FI 114-sec DRO 6-sec & FI 114-sec DRO 6-sec & $43-52$ \\
VI 50-sec & CRF & \\
FI 114-sec DRO 6-sec & - & $61-70$ \\
VI 50-sec & FI 2-min \\
FI 1 14-sec DRO 6-sec & - & $79-88$ \\
VI 50-sec & DRO 6-sec & \\
FI 114-sec DRO 6-sec & - & $97-106$ \\
VI 50-sec & FI 114-sec DRO 6-sec \\
\hline
\end{tabular}


Fig. 1. Representative cumulative records (Rat D4). All records are responding in initial component of chained schedule, except $C$, which is responding in terminal component. Stimulus presentations are indicated by downward movement of recorder pen. In Records E, F, G, and H, st imulus presentations followed by primary reinforcement indicated by marks below the record.

engendered positively accelerated responding on Lever 1. A typical performance (Rat D4) is shown in Fig. 1, A. When the schedule was changed to chain FI 2-min FI 2-min, the rate on Lever 1 decreased, and there was some disruption of positively accelerated responding (Record B in Fig. 2). Responding on Lever 2 during the same period was maintained at a high rate (Record C).

When the DRO contingency was in effect on Lever 1, rate was near zero. A typical record is shown in Fig. 1, D. Added presentations of the stimulus on VI 50 -sec concurrently with FI 114-sec DRO 6-sec resulted in a marked increase in rate on Lever 1 (Record E). Rate on Lever 1 under the concurrent schedule was higher with CRF on Lever 2 than with FI 2-min on Lever 2. Rate on Lever 1 under the concurrent schedule was not affected when a DRO 6-sec contingency on Lever 2 was substituted for CRF. In two of the four rats, rate on Lever 1 under the concurrent schedule was not affected when FI 114-sec DRO 6-sec on Lever 2 was substituted for

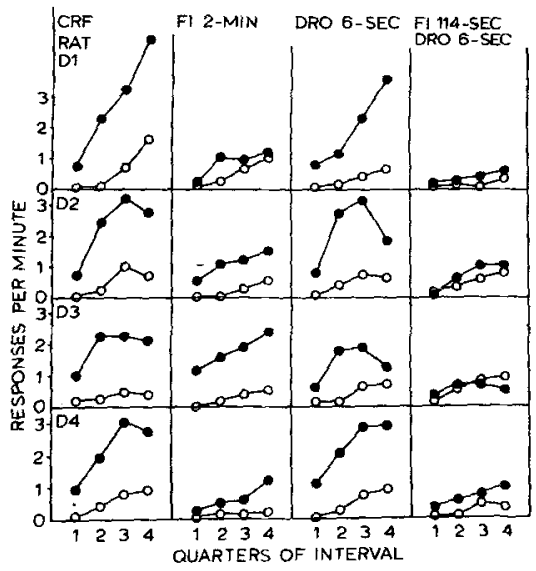

Fig. 2. Mean response rate in initial component in each quarter of $2-\mathrm{min}$ fixed interval. Open circles: stimulus presented on FI 114-sec DRO 6-sec with subsequent primary reinforcement. Solid circles: stimulus presented concurrently on FI 114-sec DRO 6-sec with subsequent primary reinforcement and VI 50-sec without subsequent primary reinforcement.

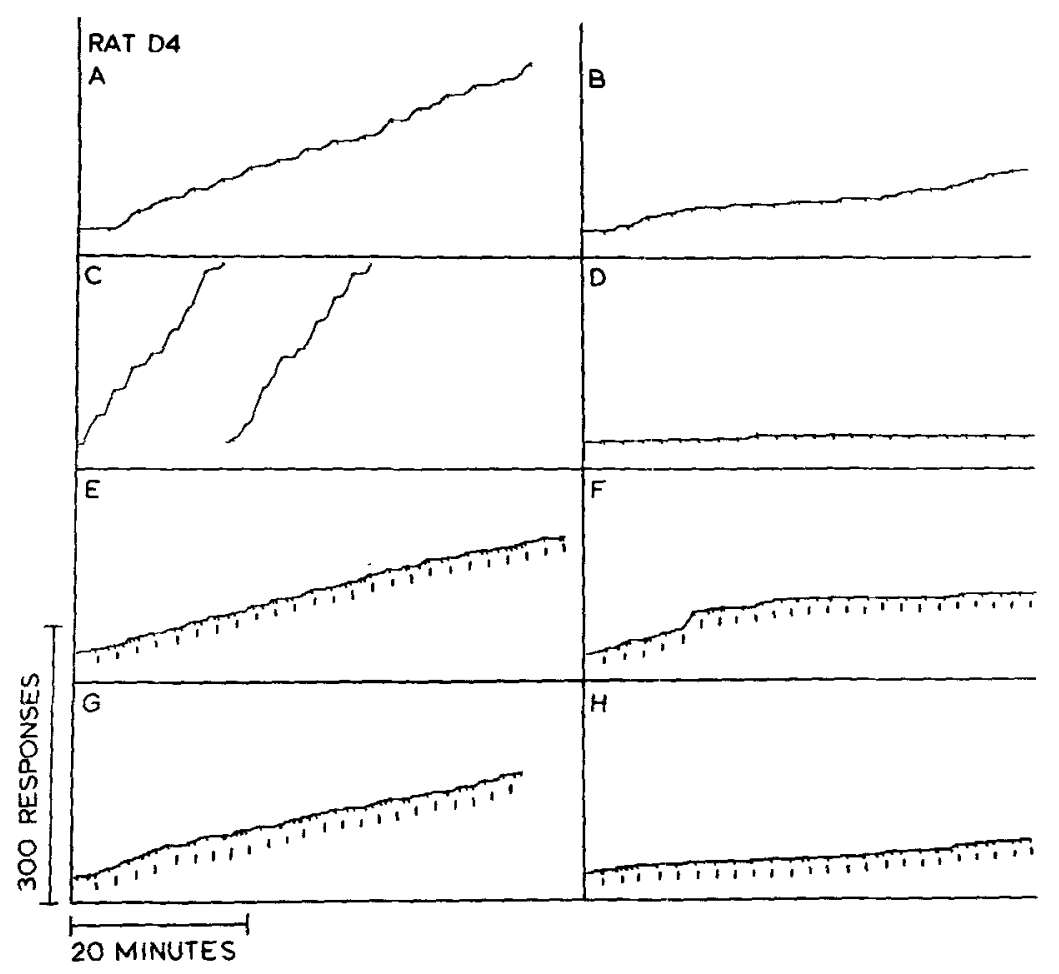

FI 2-min; in two rats, rate decreased. Records F, G, and $H$ of Fig. 1 show typical performances (Rat D4) under the concurrent schedules. The schedule on Lever 2 was FI 2-min in Record F, DRO 6-sec in Record G, and FI 114-sec DRO 6-sec in Record H. Performance of all rats under the concurrent schedules is summarized in Fig. 2, which shows mean rate on Lever 1 in each quarter of the 2-min fixed interval over the last six sessions under each procedure.

The results of this experiment were consistent with findings with related techniques, in which rate in the initial component of chained schedules is lower than rate in the terminal component (Kelleher \& Gollub, 1963). The present experiment, together with previous experiments (Zimmerman, 1969b,c), indicated that added presentations of a stimulus controlling terminal-component responding in a chained schedule can have effects comparable to those found under various brief stimulus procedures in the pigeon. Under conditions in which rate in the initial component of a chained schedule is low, it can be increased considerably by added brief presentations of the stimulus that controls second-component responding. In the present experiment, the schedule in the second component was changed, and it was found that CRF and DRO 6-sec brought about a greater increase in first-component responding than did FI 2-min or FI 114-sec DRO 6-sec. It is possible that the reinforcing capacity of a stimulus is greater if the second-component schedule maintains a high frequency of primary reinforcement, and it does not seem to depend on a specific response being made in the second component. REFERENCES

BYRD, L. D., \& MARR, M. J. Relations between patterns of responding and the presentation of stimuli under second-order schedules. Joumal of the Experimental Analysis of Behavior, $1969,12,713-722$.

KELLEHER, R. T. Conditioned reinforcement in second-order schedules. Joumal of the Experimental Analysis of Behavior, 1966, 9 , 475-485.

KELIEHER, R. T., \& GOLLUB, L. R. A review of positive conditioned reinforcement. Journal of the Experimental Analysis of Behavior, $1962,5,543-597$.

ZIMMERMAN, D. W. Concurrent schedules of primary and conditioned reinforcement in rats. Journal of the Experimental Analysis of Behavior, 1969a, 12, 261-268.

ZIMMERMAN, D. W. Patterns of responding in a chained schedule altered by conditioned reinforcement. Psychonomic Science, $1969 \mathrm{~b}$, $16,120-122$.

ZIMMERMAN, D. W. Responding in chained schedules maintained by conditioned reinforcement with and without terminal primary reinforcement. Psychonomic Science, $1969 \mathrm{c}, 17, \mathrm{1} 85-187$.

ZIMMERMAN, J., HANFORD, P. V., \& BROWN, W." Effects of conditioned reinforcement frequency in an intermittent free-feeding situation. Joumal of the Experimental Analysis of Behavior, 1967, 10, 331-340.

\section{NOTE}

1. This research was supported by Grant APA252-2057-13 from the National Research Council of Canada. 